\title{
Planejamento e Planos de Educação na Espanha: evolução da produção acadêmica e científica 1978-2016*
}

Donaldo Bello de Souza a

\section{Resumo}

O artigo inscreve-se no campo das políticas públicas de Educação Básica na Espanha, com foco na problemática do seu planejamento. A partir de levantamento documental exaustivo, cobrindo certa produção acadêmica e científica publicada neste país (1978-2016), traça um balanço quantitativo e sua evolução com base nas categorias Planejamento da Educação e Planos para a Educação. Como principal conclusão, identifica: i) repercussões dos processos de regulação supranacionais, traduzidos pelo crescente declínio do interesse por estudos relativos ao planejamento da Educação e, a um só tempo, ascensão de estudos que unicamente discutem metas de Planos de Educação; ii) fragmentação do planejamento em uma série de planos pontuais, quase sempre desvinculados entre si; e, ainda, iii) processos pouco participativos de construção desses planos, portanto, à margem de sua discussão e elaboração sociopolítica.

Palavras-chave: Planejamento da Educação. Planos de Educação. Educação Básica. Espanha.

\section{Introdução}

É possível caracterizar o Planejamento da Educação como um ato não improvisado e não subjetivo, consistindo numa tomada de decisão calçada em base legal, com "conhecimento da realidade presente, com intencionalidades respaldadas nas aspirações sociais, em relação ao futuro desejado e com avaliação dos

\footnotetext{
* Este artigo discute alguns dos resultados parciais de investigação realizada, no período de julho de 2017 a fevereiro de 2018, no âmbito do Departamento de Pedagogia da Facultad de Ciencias de la Educación da Universidade de Granada (UGR), Espanha (SOUZA, 2018), viabilizada por meio de Bolsa de Estágio Sênior no Exterior concedida pela Coordenação de Aperfeiçoamento de Pessoal de Nível Superior/ Ministério da Educação (Capes/MEC), também com o apoio do Programa de Capacitação Docente (Procad) da Sub-Reitoria de Pós-graduação e Pesquisa da Universidade do Estado do Rio de Janeiro (SR2/Uerj), tendo também produzido dois outros estudos preliminares (SOUZA; BATISTA, 2017, 2018).

a Universidade do Estado do Rio de Janeiro, Rio de Janeiro, RJ, Brasil.
} 
impactos das alternativas de ação" (BORDIGNON, 2014, p. 33). É igualmente definido como um processo sistemático, contínuo e aberto, que serve para dispor formas de ação que se aplicam a qualquer campo (FUENTES PÉREZ, 1986a). Do ponto de vista formal, as decisões tomadas ao longo de um processo de planejamento são consolidadas num Plano de Educação, podendo ser traduzidas na definição de etapas (metas) e ações (estratégias) relativas ao caminho a ser seguido (BORDIGNON, 2014).

Um plano diferencia-se do planejamento propriamente dito na medida em que, enquanto o primeiro "coordena, racionaliza e dá unidade de fins à atuação do Estado, este garante a coerência entre meios e fins, sendo expressão da política geral do Estado" (MARTINS, 2012, p. 96), distanciando-se de uma intervenção conjuntural ou eventual, motivo pelo qual os planos podem cumprir diversas funções nas instituições políticas, econômicas e sociais, dependendo do seu contexto de elaboração e da correlação de forças sociais que os enseja (VIEIRA, 2014).

Assim, a constituição de um Plano de Educação pressupõe a elaboração de um diagnóstico sobre a realidade educacional ao qual o planejamento corresponde, ou seja, pauta-se na análise de dados quantitativos e em caracterizações e contextualizações qualitativas, compreendendo a especificação de problemas, dificuldades e perspectivas para uma dada realidade educacional. É a partir do diagnóstico, portanto, que se estabelecem as escolhas para a formulação das políticas que vêm dar corpo ao plano propriamente dito, em termos das suas decisões, com maior fidedignidade em relação a uma situação educacional específica (BORDIGNON, 2014; ROCHA; MONLEVADE; AGUIAR, 2006).

As metas de um plano consistem nos seus objetivos fins, ou seja, trazem à vista as decisões assumidas no plano, no sentido de explicitarem as intenções e ações das políticas educacionais a serem adotadas para a solução dos problemas identificados na etapa diagnóstica, com quantitativos e prazos mensuráveis e, ainda, com indicação das estratégias a serem cumpridas ao longo do seu processo de execução (MONLEVADE, 2002). Já as estratégias definem os objetivos meios de um plano, viabilizando o alcance de suas metas, expondo a definição de ações, recursos e condições favoráveis disponíveis para o avanço na direção das decisões tomadas (BORDIGNON, 2014).

Nestes termos, com base em levantamento documental exaustivo, que cobre certa produção acadêmica e científica publicada na Espanha ao longo de 38 anos (1978-2016), o presente artigo traça um balanço quantitativo sobre os trabalhos 
selecionados, e analisa sua evolução com base em duas categorias centrais: Planejamento da Educação e Planos para a Educação, relativos à Educação Básica ${ }^{1}$.

Para tanto, esse estudo se encontra dividido em quatro seções fundamentais. Após sua introdução, destacam-se os aspectos metodológicos gerais que nortearam o levantamento documental para, em seguida, discutir os seus resultados a partir da evolução histórica das publicações selecionadas, organizando-as em três períodos (décadas de 1980-1990, 2000 e 2010). A quarta e última seção estabelece as conclusões do estudo, buscando caracterizar a produção inventariada.

\section{Aspectos metodológicos}

Parece não haver consenso na literatura sobre pesquisas qualitativas quanto à necessidade de definição e emprego de um esquema teórico a priori que sirva ao processo investigativo. Todavia, a definição de um quadro teóricoconceitual, nos termos das linhas de análise, dos conceitos tematizados e dos princípios e concepções teóricas existentes, pode ser considerada fundamental para a configuração de um referencial categorial articulado à escolha, seleção e, sobretudo, análise das referências a serem coletadas em estudos que se pautam em levantamentos documentais, não impedindo, contudo, que outras categorias venham a ser empregadas a posteriori.

No âmbito da investigação que originou o presente trabalho, a seleção das referências não se limitou à verificação da presença de categorias unicamente determinadas a priori, de modo a superar eventuais insuficiências de resultados do levantamento, especialmente em face do grau de exaustividade esperado e da expectativa de encontro de outras questões de relevo relacionadas à problemática enfocada. Por este motivo, empregou-se um modelo de análise dito de "grade mista” (LAVILLE; DIONNE,1999), ou seja, apesar de já se possuir, a priori, a definição de duas categorias temáticas centrais ${ }^{2}$, o levantamento documental levou em consideração, após o seu primeiro ciclo de realização, um conjunto

\footnotetext{
A Educação Básica espanhola é composta pela Educação Primária e Secundária obrigatória, com dez anos de duração, dos seis aos 16 anos. Assim como no Brasil, principia por meio da Educação Infantil que compreende, em dois ciclos, crianças até os 6 anos de idade, momento a partir do qual é introduzida a educação obrigatória, ainda sendo garantida, a partir dos 3 anos de idade, a gratuidade da educação formal. A Educação Primária, abarca crianças dos 6 aos 12 anos de idade, antecedendo à Educação Secundária, que compreende: a chamada Educação Secundária Obrigatória (ESO) (dos 12 aos 16 anos), o Bacharelado, última etapa da Educação Secundária, mas de caráter voluntário (dos 16 aos 18 anos) e a Formação Profissional de Grau Médio, para jovens que o iniciem com o mínimo de 15 e o máximo de 17 anos (SOUZA; BATISTA, 2017).

2 No primeiro ciclo do levantamento documental a consulta às bases de dados/portais eletrônico sem tela se pautou no emprego de sete termos em idioma espanhol: os três primeiros derivados do termo em português Planejamento da Educação (Planificación Educativa, Planificación de la Educación, e Planificación Educacional), enquanto que os outros quatro derivados do termo, também em português, Planos para a Educação (Plan de Educación, Plan Educativo e Plan Educacional).
} 
mais amplo de elementos teórico-empíricos que vieram a expor relevância para a investigação. Esses elementos emergiram do exame preliminar das referências inicialmente selecionadas no primeiro ciclo do levantamento, vindo a ser configuradas como subcategorias temáticas e empregadas em um segundo ciclo de busca, ambos os ciclos orientados por três fases, a saber, identificação, seleção e depuração e, ainda, complementação.

A fase de identificação das referências implicou consulta, via internet, ao total de 14 bases de dados/portais eletrônicos ${ }^{3}$, empregando como critério inicial de triagem: i) a coesão do título da referência identificada em relação às duas categorias temáticas centrais do levantamento; ii) a natureza da fonte (se artigo em revista, tese de doutorado, livro no todo ou capítulo de livro); iii) o idioma (unicamente o espanhol), e, ainda, a data de publicação das referências (entre 1978 e 2016) ${ }^{4}$.

A fase de seleção objetivou examinar as referências identificadas na fase inicial, de modo a verificar, de fato, sua pertinência em relação aos objetivos do levantamento. Tal procedimento se pautou no exame dos resumos autorais constantes das teses de doutorado e dos artigos publicados em revistas científicas, não se tendo aplicado aos livros no todo e aos capítulos de livros. Em seguida a esta seleção, procedeuse à sua depuração, isso por meio de visita à Biblioteca da Faculdade de Ciências da Educação da UGR, à Biblioteca de Educação do Mecde, e, ainda, à BNE, estas duas últimas em Madrid. A consulta in loco se aplicou, portanto, a todas as referências identificadas na primeira fase do levantamento, via Internet, mas que não disponibilizavam os seus respectivos conteúdos na íntegra, com vistas ao refinamento da seleção de obras pertinentes a tal levantamento. Mais uma vez, se aplicou o critério de seleção adotado nas fases anteriores.

Concluída as duas fases descritas, passou-se à sua complementação, caracterizada pela definição das subcategorias teórico-empíricas emergentes deste primeiro ciclo de levantamento, assim como dos seus respectivos descritores. Tal definição viabilizou a execução de um segundo ciclo de buscas, resultando nova consulta

\footnotetext{
3 i) Bases de dados/portais eletrônicos brasileiros: Educ@: Publicações on-line de Educação, Periódicos Capes/ MEC; ii) Bases de dados/portais eletrônicos espanhóis: Base de Datos de Tesis Doctorales (Tese o/MECD), Biblioteca da Facultad de Ciencias de la Educación (FCE/UGR), Biblioteca de Educación del Ministerio de Educación, Cultura y Deporte (MECD), Biblioteca Nacional de España (BNE), Catálogo de Publicaciones Administración General del Estado (Cpage), Catálogo de Publicaciones Mecd, Dialnet, Red AGE - Red de Apoyo a la Gestión Educativa, Red de Bibliotecas Universitarias Españolas (Rebiun), Sumarios ISOC (Ciencias Sociales y Humanidades) - Agencia Estatal Consejo Superior de Investigaciones Científicas (CSIC)/Ministerio de Economía y Competitividad; iii) Outras Bases de dados/portais eletrônicos: Google Acadêmico, Scientific Electronic Library Online (SciELO).

4 Tal período encontra-se compreendido entre o ano de promulgação da Constituição espanhola (ESPAÑA 1978), marco fundamental para a redemocratização do país, e aquele que precede o início do levantamento documental propriamente dito (2017).
} 
à Internet, nos moldes realizados nas três fases anteriores, de forma a identificar novos estudos coesos a essas subcategorias temáticas, contribuindo para o aprofundamento e a exaustividade do levantamento documental. Neste sentido, foram empregados termos específicos, referentes tanto a algumas das subcategorias identificadas, quanto a alguns dos descritores de outras subcategorias também observadas no primeiro ciclo de levantamento.

Considerando os dois ciclos do levantamento documental, registrou-se consulta total a 12.930 registros pertencentes às 14 bases de dados/portais utilizados, dos quais as maiores parcelas se fazem notar no âmbito da Dialnet (5.286), Rebiun (4.370) e Biblioteca do Mecd (1.565) que, somadas, exprimem cerca de 87\% (11.221) dessas ocorrências, denotando serem importantes fontes de dados para este tipo de estudo documental, em particular para as categorias empregadas.

Contudo, em que pese o fato de as ocorrências ao longo do processo de busca se terem mostrado quantitativamente elevadas, ao lado do esforço depreendido no segundo ciclo em se empregar termos de busca com maior especificidade temática, observa-se que apenas $0,7 \%$ (97) do total de referências consultadas (12.930) se mostrou efetivamente coeso à temática do estudo, $40 \%$ (39) correspondendo à categoria Planejamento da Educação, enquanto que 60\% (58) à categoria Planos para a Educação. Isso sugere haver um maior interesse da produção espanhola para com a consolidação das decisões tomadas ao longo do planejamento (Planos), e menos em relação à discussão sobre aquele processo e suas intencionalidades (Planejamento). Ainda, em relação ao total das 97 referências selecionadas, cerca de $60 \%$ (58) concernem a artigos publicados em revistas, 29\% (28) dizem respeito a livros no todo e a capítulos de livro, seguidos de apenas $11 \%$ (11) teses de doutorado.

\section{Resultados por evolução história das publicações}

O Gráfico 1 apresenta a evolução do quantitativo relativo à produção selecionada ao longo dos 38 anos enfocados pelo levantamento documental (1978-2016), por cada uma das duas categorias temáticas centrais do estudo, sinalizando as Linhas de Tendência (LT) correspondentes.

A partir do Gráfico 1, é possível afirmar que o número de referências associadas às duas categorias basais do levantamento documental expõe diversas oscilações ao longo do tempo, nesse sentido indicando momentos de ascensão, queda ou mesmo períodos de ausência de publicações sobre essas temáticas. Tais irregularidades podem estar significando que o campo investigativo sobre o planejamento educacional (no seu sentido lato) na Espanha ainda não se encontra consolidado, 
mostrando-se incipiente e instável em relação à objetivação das políticas públicas de planejamento educacional emanadas pelo governo central e pelas Comunidades Autônomas e, na esfera internacional, aos processos transnacionais de regulação que afetam este tipo de planejamento.

Gráfico1 - Número de referências selecionadas, por ano de publicação e categoria temática central-1978-2016

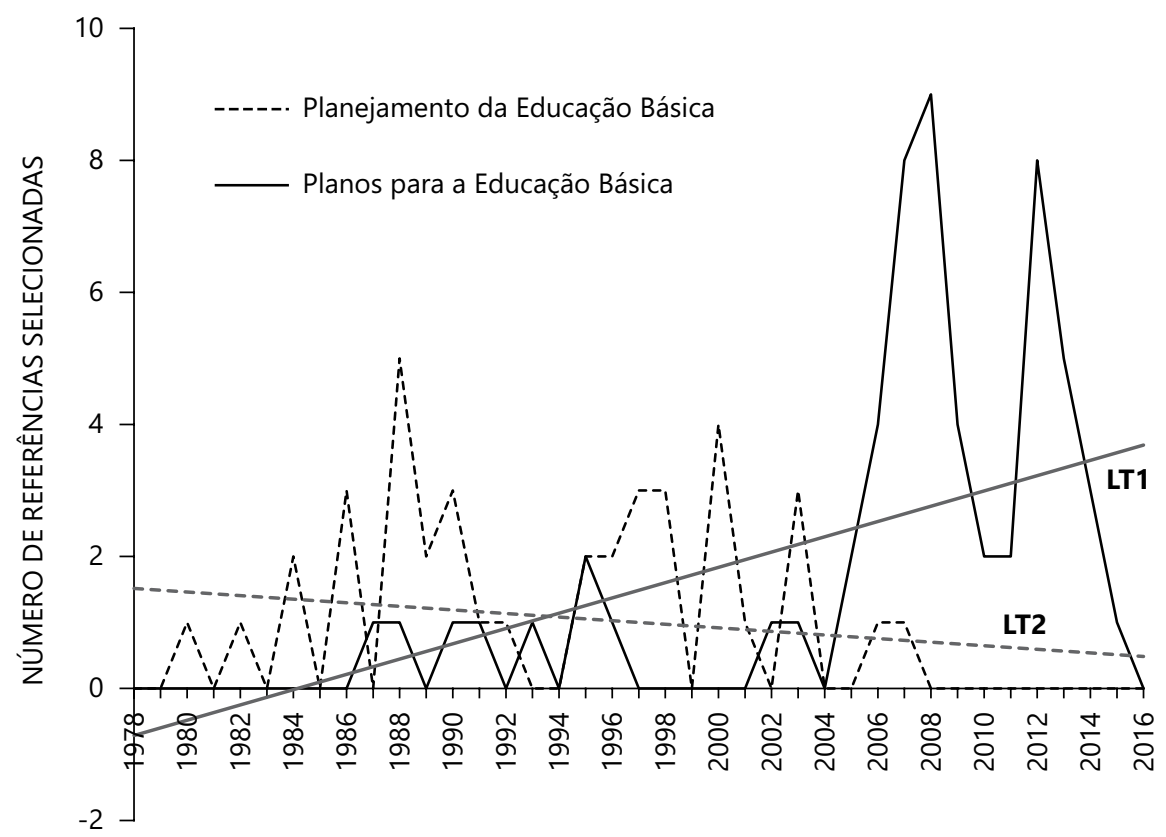

ANO DE PUBLICAÇÃO

Fonte: Pesquisa de Campo, 2017-2018

Em que pese o fato de ambas as categorias do levantamento apresentarem oscilações, é importante preliminarmente observar que a evolução dos estudos em questão irá diferenciar-se em função do crescimento apresentado: enquanto que, ao longo do tempo, se constata o decréscimo dos trabalhos sobre o Planejamento da Educação Básica (veja-se LT2), até que, em 2008, não mais sejam identificados, os trabalhos sobre os Planos para a Educação Básica, embora distinguidos apenas a partir de 1986, expõem crescimento ascendente ao longo de todo o período examinado (veja-se LT1). Ou seja, a importância atribuída aos estudos sobre os Planos de Educação na Espanha vai, progressivamente, se sobrepondo ao valor do exame da problemática do planejamento, expressão de um movimento 
contraditório que, não apenas inverte certa ordem lógica entre essas duas dimensões, mas promove a sua mútua dissociação, conforme abordado mais adiante. Além dessas constatações, o exame do Gráfico 1 suscita algumas outras considerações centrais, circunscritamente ao recorte temporal adotado na pesquisa (1978-2016), conforme elencadas a seguir ${ }^{5}$.

\subsection{Décadas 1980-1990: mais planejamento, menos planos}

Desconsiderando-se os dois anos iniciais cobertos pelo levantamento documental (1978 e 1979), que não aportaram estudos, observa-se que, ao longo das décadas de 1980 e 1990, houve uma significativa superioridade do quantitativo de referências sobre o Planejamento da Educação (29), em relação aos estudos que versam sobre os Planos de Educação (sete). Os primeiros trabalhos sobre Planos de Educação começam a ser publicados, justamente, logo em seguida à adesão da Espanha à então Comunidade Econômica Europeia (CEE), em $1^{\circ}$ de janeiro de $1986^{6}$, com defasagem, portanto, de cerca de sete anos, em relação aos estudos iniciais sobre o Planejamento da Educação Básica nesse país, constatados a partir de 1980.

Verifica-se também que a preocupação dessas primeiras referências sobre os planos espanhóis de educação remete, em exclusivo, aos Planos para a Educação de Pessoas Adultas e aos Planos para a Educação Infantil, isso num contexto também marcado pela aprovação da Lei Orgânica ${ }^{\circ}$ 8, de 3 de julho de 1985, reguladora do Direito à Educação (Lode) (ESPAÑA, 1985) e da Lei Orgânica $n^{\circ} 1$, de 3 de outubro de 1990, de Ordenamento Geral do Sistema Educativo (Logse) (ESPAÑA, $1990)^{7}$. Os estudos sobre os Planos para a educação de pessoas adultas tomarão por objeto o Plano de Educação Permanente de Adultas (Pepa) ${ }^{8}$ (JABONERO BLANCO, 1995) e alguns dos planos regionais, como o de La Rioja (ALONSO

\footnotetext{
Em função das limitações editoriais do presente artigo, procedeu-se à indicação de uma única referência por cada subcategoria temática abordada. Para acesso ao conjunto completo das referências selecionadas pelo levantamento, veja-se Souza (2018).

6 Disponível em: https://europa.eu/european-union/about-eu/countries/member-countries/spain_pt. Acesso em: 10 set. 2019.

7 A Lode, entre outros aspectos, visou à democratização do acesso aos diferentes níveis de ensino na Espanha, priorizando a universalização da escolarização de crianças e jovens entre 2 e 16 anos, o aumento da taxa de escolarização para jovens com idade superior a 16 anos e o desenvolvimento de programas de educação permanente (ESPAÑA, 1985). Já a Logse irá organizar a Educação Infantil, a Primária e a Secundária neste país (ESPAÑA, 1990). De acordo com Di Pierro (2000), a partir das inovações educacionais levadas a efeito por este ordenamento jurídico, a Espanha logrou superar concepções de educação de adultos de caráter caracteristicamente compensatório, substituindo-a por um paradigma de educação continuada, ao passo da promoção da descentralização educativa, integração e adoção do território como unidade de planejamento da oferta educativa.

8 O Pepa começou a ser implantado na Espanha pelo governo central, em 1990, com duração de cinco anos, abraçando ações relativas à alfabetização de mulheres adultas nos territórios de gestão do então Ministerio de Educación y Ciencia (JABONERO BLANCO, 1995).
} 
MATURANA et al., 1995) e de Murcia (ALHAMA PIQUERAS, 1987), enquanto os de Educação Infantil focarão o Plano Experimental de Educação Infantil ${ }^{9}$ (OLAYA VILLAR, 1996).

Já as primeiras referências selecionadas sobre o Planejamento da Educação Básica na Espanha refletem interesse pontual em discutir propostas para o planejamento local da educação (SANZ ORO, 1980), assim como analisar as relações do planejamento da educação com os sistemas de ensino (MONTERO ESPINOZA, 1984) e com o emprego (QUINTANA CABANAS, 1984). Em seguida, ainda nessa mesma década (1980), despontam estudos conceituais sobre o planejamento da educação (FUENTES PÉREZ, 1986a) e os que realizam balanços sobre os seus modelos gerais (GRAO RODRÍGUEZ, 1988), que abordam os seus componentes (MARTÍNEZ SALAZAR, 1988) e vínculos com as reformas educacionais (ASTORGANO RUIZ, 1989). Ao lado desses, sobressaem trabalhos que formulam propostas de planejamento da educação aos níveis regionais (FUENTES PÉREZ, 1986b) e também locais (TEMRICART, 1988), num relativo esforço do conjunto desta literatura em definir, em meio à aprovação da Lode, os rumos desse tipo de planejamento no país.

Embora em relação aos períodos seguintes os anos 1980 indiquem uma maior concentração de estudos sobre o Planejamento da Educação, a década de 1990 continuará a apresentar estudos vinculados às mesmas temáticas anteriormente identificadas, agora incluindo as vinculações do planejamento da educação com a diversidade (GRAO FONTAO, 1998), coerentemente ao momento em que a problemática do multiculturalismo assume relevo no cenário europeu, e, ainda, com a educação permanente (BUJ GIMENO, 1992), de modo coeso aos efeitos da aprovação da Lode e da Logse, assim como em relação à disseminação no país dos Planos para a Educação de Pessoas Adultas, como o Pepa.

\subsection{Década 2000: menos planejamento, mais planos}

Os idos de 2000 trazem à vista uma importante inversão na evolução das referências examinadas, sinalizando um vertiginoso declínio dos estudos sobre o Planejamento da Educação, de 29 para 10 referências (-65\%), os quais, a partir de 2008, não mais serão notados, dando lugar ao expressivo crescimento dos trabalhos que tomam por alvo os mais variados Planos para a Educação Básica, de sete para 28 referências $(+400 \%)$. Consiste numa fase que se mostrará mais produtiva não apenas em decorrência da elevação do quantitativo desses estudos, mas também na perspectiva da ampliação do leque temático e do foco investigativo correlato.

\footnotetext{
9 O Plano Experimental de Educação Infantil foi iniciado pelo Ministerio de Educación y Ciencia, em abril de 1985, visando a reforma da Educação Infantil na Espanha (OLAYA VILLAR, 1996).
} 
Nesse período, os trabalhos que versam sobre o Planejamento da Educação, embora diminutos, dão continuidade àqueles sobre a problemática da diversidade - já notados no limiar da década anterior -, quer sob perspectiva institucional (SEBASTIAN HEREDERO, 2003), quer em termos dos processos participativos que podem dele resultar (HERNÁNDEZ CASTILLA, 2003).

Por sua vez, nessa mesma década, os trabalhos sobre os Planos para a Educação Básica vão apresentar os primeiros picos de crescimento do seu quantitativo. Principiados em 2005, esses picos virão a atingir o seu valor máximo em 2008, no contexto de aprovação da Lei Orgânica n ${ }^{\circ} 2$, de 3 de maio de 2006, de Educação (LOE) (ESPAÑA, 2006) ${ }^{10}$. Tal lei, em paralelo aos novos planos que irão surgir, suscitará a efetivação de novos estudos no campo, com quantitativos relativamente expressivos, como os que passam a examinar: os Planos de Educação compensatória, notadamente o Plano de Reforço, Orientação e Apoio (Proa) (MANZANARES MOYA, 2007) ${ }^{11}$; os Planos para a convivência e segurança escolar ${ }^{12}$, na perspectiva do exame de suas configurações nacional e territoriais (DÍEZ PRIETO, 2006) e de formulação de propostas (TORREGO SEIJO, 2008); os Planos de fomento à leitura ${ }^{13}$ (MAÑÀ TERRÉ, 2008) e, de forma incipiente, os Planos de Educação para a diversidade ${ }^{14}$ (RAMOS ALÍA, 2008).

\footnotetext{
${ }^{10}$ A LOE regulou o ensino espanhol no atendimento de suas diferentes faixas etárias, abarcando a Educação Infantil, primária e secundária obrigatória, o bacharelato, a formação profissional, o ensino de idiomas, artes e desporto, a educação de pessoas adultas e o ensino universitário (ESPAÑA, 2006). Seguindo recomendações da Comissão e do Parlamento Europeu, incorporou as Competências Básicas como novo componente curricular e novo enfoque pedagógico na Espanha (MONARCA et al., 2016). Ainda em vigência, esta lei veio a ser parcialmente modificada pela Lei Orgânica n. 8, de 9 de dezembro de 2013, para a Melhoria da Qualidade Educativa (em espanhol Lomce) (ESPAÑA, 2013).
}

11 O Proa consiste em um plano posto em prática por meio de mecanismos de cooperação territorial entre os governos central e regionais, destinando-se aos Centros de Educação Primários e Secundários da Espanha, tendo iniciado em 2005 e finalizado em 2012. Em linhas gerais, visou apoiar os Centros Educativos com a disponibilização de recursos articulados à redução dos fatores entendidos como geradores da desigualdade dos resultados escolares, além de garantir a atenção aos coletivos que expõem maior vulnerabilidade, prevenindo riscos de exclusão social (ESPAÑA, 2007).

12 Com a LOE, os Planos para a convivência escolar vieram a se tornar obrigatórios nos Projetos Educativos dos Centros Escolares espanhóis, vindo a favorecer sua elaboração regional pelas Comunidades Autônomas, em especial na primeira década de 2000, ao lado dos acordos e pactos sociais voltados para uma convivência dita pacífica nos Centros Educativos desses territórios (DÍEZ PRIETO, 2006).

${ }^{13} \mathrm{O}$ primeiro plano de fomento à leitura apresentado pelo Ministério da Educação, em escala nacional, se desenvolveu no período 2001-2004, tendo sido reeditado no período 2005-2008 e continuado, por meio de algumas de suas ações, ao longo dos anos seguintes. Mais recentemente, em 2017, o Ministério de Educación, Cultura y Deporte laçou uma nova versão do plano, o Plan de Fomento de la Lectura 2017-2020: Leer te da vidas extra, caracterizando-o como um plano de estímulo à demanda, constituído por linhas estratégicas e programas específicos, combinando medidas novas com algumas já existentes (ESPAÑA, 2017).

${ }^{14}$ Os Planos de Educação para a diversidade, ou também denominados Planos de Atenção à Diversidade (PAD), abordam, em âmbito central, regional e local, a problemática da inclusão educacional sob vários ângulos, especialmente em termos do atendimento das necessidades de todos os alunos em sala de aula, assim como específicas de atenção à diversidade, tal como ocorre com os alunos com altas capacidades, isto segundo parâmetros e qualidade (RAMOS ALÍA, 2008). 


\subsection{Década 2010: mais planos, nenhum planejamento}

Os anos 2010 compreendem um período, no qual já não se observa nenhum estudo sobre o Planejamento da Educação, acompanhado de um ligeiro decréscimo de trabalhos na esfera dos Planos para a Educação, de 28 para 22 referências $(-21 \%)^{15}$ as quais, a partir de 2012, sofrerão uma vertiginosa queda no seu quantitativo, até indicar, em 2016, a inexistência de estudos, também, sobre Planos para a Educação.

No período em questão, os estudos sobre Planos para a Educação são marcados: pela continuidade dos estudos sobre o Proa, agora caracteristicamente de cunho avaliativo (MANZANARES MOYA; ULLA DÍEZ, 2012); pela ampliação do escopo dos estudos relacionados aos Planos de educação para a igualdade de gênero ${ }^{16}$ que, embora escasso se caracteristicamente descritivos nas décadas anteriores, passam a objetivar a percepção de docentes (REBOLLO CATALÁN; VEGACARO; GARCÍA PÉREZ, 2011) e, também, a realizar avaliações de versões regionais e locais desse plano (DÍAZ FERNÁNDEZ, 2016); pelo alargamento dos estudos sobre os Planos de educação para a diversidade que, avançando em relação às abordagens sobre a sua configuração no âmbito dos Centros Educativos, se inclinam para as suas versões regionais (RODRÍGUEZ GONZÁLEZ, 2013).

A um só tempo, notam-se abordagens iniciais sobre novos planos, quase sempre com frequência unitária, como os Planos regionais e locais para a autonomia dos Centros Educativos (GARCIA ALEGRE; CASALS, 2012) os Planos de acolhida linguística e cultural (RINCÓN VERDERA; VALLESPIR SOLER, 2010), os Planos para a formação profissional (MIGUEL DÍAZ et al., 2012) e os Planos educativos de entorno (MARTÍNEZ LOBERA; BERNABÉ PÉREZ; BLANCH HUGUET, 2006).

\section{Considerações finais}

Conforme sinalizado por Maroy (2005), ainda que os sistemas de educação europeus sejam bastante diferenciados, encontram-se vulneráveis a pressões externas de ordem econômica, social e política que, de acordo com autores como Barroso (2006), Dutercq (2005), Steiner-Khamsi (2002), entre outros, resultam de processos de regulação transnacionais como os praticados por organismos

\footnotetext{
15 Esta redução pode ser considerada relativamente inexpressiva, em especial se levado em conta o fato de que na década de 2010 o levantamento apenas cobriu a sua primeira metade (2010-2016), desconhecendo-se, até o presente momento, o perfil dos trabalhos publicados nos seus últimos quatro anos.

${ }^{16}$ Ao nível central do Estado, destaca-se o Plan de Acción para la Igualdad de Oportunidades de las Mujeres 1988/1990, elaborado pelo Consejo Rector del Instituto de la Mujer, e aprovado pelo Consejo de Ministros, em 1987 (ESPAÑA, 1987) que, por meio de diversas metodologias, enfoques e objetivos, irá repercutir na elaboração de planos regionais e locais similares.
} 
multilaterais de financiamento e órgãos voltados para a cooperação técnica. Nesse sentido, tratam-se de estruturas supranacionias "que, mesmo não assumindo formalmente um poder de decisão em matéria educativa, controlam e coordenam, através das regras e dos sistemas de financiamento, a execução das políticas nesse domínio [...]” (BARROSO, 2006, p.45).

Ou seja, não por acaso, a crescente tendência de declínio dos estudos sobre o Planejamento da Educação Básica na Espanha parece denotar, no âmbito do campo, a redução do interesse investigativo sobre as ações e processos decisórios dos governos nacional, regionais e locais, e, na esfera da formulação das políticas públicas e de sua prática, o próprio esvaecer das ações governamentais de planejamento educacional. Pelo fato da ocorrência do seu deslocamento para a esfera supranacional, o Planejamento da Educação Básica sugere dar lugar na produção o acadêmica e científica espanhola ao estudo de suas decisões, tipicamente consubstanciadas em uma extensa gama de Planos para a Educação Básica, não necessariamente espúrios à realidade espanhola, mas: i) que não refletem processos democráticos de participação sociopolítica, especialmente em termos da definição de seus princípios e objetivos, metas e estratégias mais gerais, agora cunhados nos espaços de regulação das políticas econômicas e sociais europeias, e ii) desarticulados entre si, na medida em que são elaborados em diferentes momentos, sob distintas perspectivas, com objetivos e metas que visivelmente não se comunicam ou estabelecem mútuas vinculações, à margem de uma perspectiva totalizadora da realidade educacional deste país e, por conseguinte, de um planejamento educacional de maior consistência sistêmica.

Outra dimensão que reforça as hipóteses anteriores consiste no surgimento, em 1986, ou seja, a partir da adesão da Espanha à então CEE, dos estudos sobre os Planos para a Educação Básica, que ao longo das décadas seguintes irão contemplar temáticas cujos trabalhos sobre o Planejamento da Educação sequer chegaram a tangenciar, como, por exemplo, gênero, educação compensatória, convivência e segurança escolar, diversidade, autonomia dos Centros Educativos, fomento à leitura, formação profissional, acolhida linguística e cultural, entre outros.

Contudo, não se pode perder de vista que esses processos de regulação supranacionais, frutos da ressignificação dos papeis dos Estados-nação e da globalização (KAZAMIAS, 2010; MASON, 2015; ROBERTSON; DALE, 2010), resultam, a um só tempo, reconfiguração dos processos de produção dessas identidades, aparentemente obscurecidas (especialmente, regionais e locais). Em outras palavras, entende-se que as políticas públicas educacionais globais, como as que possivelmente se dirigiram ao planejamento (no seu sentido lato) 
da educação na Espanha, podem expor mudanças e transformações na sua versão original, em decorrência de sua recontextualização, ou seja, dos processos de interpretação e recriação produzidos localmente por diferentes atores sociais, segundo suas histórias, experiências, valores, propósitos e interesses diversos (BALL; MAGUIRE; BRAUN, 2012; BOWE; BALL; GOLD, 1992; LIMA, 1992; 2002).Uma evidente pista disso são as versões regionais e locais dos Planos de Educação tomados por objeto por alguns dos estudos em questão, particularmente a partir da década de 2000, como, por exemplo, os Planos para a convivência e segurança escolar, de educação para a diversidade, para a autonomia dos Centros Educativos, de fomento à leitura, para Educação Infantil, entre outros.

Em síntese, o estudo realizado sugere ter trazido à vista, com ineditismo, certa produção o acadêmica e científica espanhola a respeito de duas importantes problemáticas da área da educação, em específico do campo da gestão (Planejamento e Planos para a Educação Básica), embora evidenciando: i) sua incipiência e escassez, ii) relativa fragmentação entre as fontes documentais das quais derivam e, ainda, iii) desequilíbrio entre as subcategorias que dão corpo a estas duas temáticas centrais do levantamento.

A pesquisa revela, ainda, repercussões nessa mesma literatura :i) dos processos de regulação supranacionais, traduzidos pelo crescente declínio do interesse por estudos relativos ao planejamento da educação e, a um só tempo, ascensão dos trabalhos que se restringem ao exame de objetivos, metas e estratégias consolidadas em planos de educação; ii) da fragmentação do planejamento da educação em uma série de planos pontuais, quase sempre desvinculados entre si; e, ainda, iii) de processos pouco participativos de planejamento e elaboração desses planos, no âmbito do governo central, portanto, à margem de sua discussão e elaboração sociopolítica. 


\title{
Planning and Educational Plans in Spain: the evolution of the scientific and academic production 1978-2016
}

\begin{abstract}
The article is part of the field of public policies for Basic Education in Spain, focusing on the problems concerning their planning. From an exhaustive documental survey, covering certain academic and scientific productions published in this country (1978-2016), this work draws a quantitative balance and its evolution based on the categories: Educational Planning and Plans for Education. As a main conclusion, this article identifies: i) repercussions of the supranational regulation processes, translated by the growing decline of interest in studies related to educational planning and, at the same time, rise of studies that only discuss goals of Education Plans; ii) the planning fragmentation in a series of punctual plans, almost always disconnected among each other, and also; iii) a little participatory process in the construction of these plans, therefore, on the sidelines of their discussion and socio-political elaboration.
\end{abstract}

Keywords: Educational Planning. Educational Plans. Basic Education. Spain.

\section{Planificación y Planes para la Educación Básica en España: evolución de la producción académica y científica 1978-2016}

\section{Resumen}

El artículo se refiere al campo de las políticas públicas de Educación Básica en España, centrándose en la problemática de su planificación. Basado en una encuesta documental exhaustiva, que cobre una cierta producción académica y científica publicada en este país (1978-2016), delinea un balance cuantitativo y su evolución en función de las categorías Planificación de la Educación y Planes para la Educación. Como conclusión principal, identifica: i) repercusiones de procesos de regulación supranacionales, traducidos por la creciente disminución del interés en estudios relacionados con la planificación de la Educación y, al mismo tiempo, el aumento de estudios que solo discuten objetivos del Planes de Educación; ii) fragmentación de la planificación en una serie de planes específicos, casi siempre sin relación entre sí; $y$, aún, iii) procesos participativos de construcción de estos planes, por lo tanto, aparte de su discusión y elaboración sociopolitica.

Palabras clave: Planificación de la Educación. Planes de Educación. Educación Básica. España. 


\section{Referências}

ALHAMA PIQUERAS, J. Plan regional de educación de adultos de Murcia: un análisis de datos globales. Murcia: Dirección Provincial del MEC, 1987.

ALONSO MATURANA, R. et al. Hacia un nuevo contrato educativo: la educación de adultos: un plan para La Rioja. Logroño: Consejería de Educación, Cultura, Juventud y Deportes, 1995.

ASTORGANO RUIZ, A. Ante la reforma del sistema educativo, debate, reflexión, planificación. Razón y Fe: Revista Hispanoamericana de Cultura, Madrid, n. 1.091-1.092, p. 218-222, 1989.

BALL, S.; MAGUIRE, M.; BRAUN, A. How schools do Policy: policy enactments in secondary schools. New York: Routledge, 2012.

BARROSO, J. O Estado e a educação: a regulação transnacional, a regulação nacional e a regulação local. In: BARROSO, J. (org.). A regulação das políticas públicas de educação: espaços, dinâmicas e actores. Lisboa: Educa, 2006. p. 41-70.

BORDIGNON, G. Planos de governo e políticas de estado: muitos planos, pouco planejamento. In: SOUZA, D. B.; MARTINS, A. M. (orgs.). Planos de educação no Brasil: planejamentos, políticas, práticas. São Paulo: Loyola, 2014. p. 29-53.

BOWE, R.; BALL, S. J.; GOLD, A. Reforming education and changing schools: case studies in policy sociology. London: Routledge, 1992.

BUJ GIMENO, A. La planificación intersectorial de la educación permanente. Revista Complutense de Educación, Madrid, v. 3, n. 1-2, p. 145-166, 1992. Disponível em: https://revistas.ucm.es/index.php/RCED/article/download/ RCED9292110145A/18040. Acesso em: 15 out. 2017.

DI PIERRO, M. C. Evolução recente da educação de pessoas adultas na Espanha. Educação \& Sociedade, Campinas, v. 21, n. 72, p. 233-252, ago. 2000. https://doi.org/10.1590/S0101-73302000000300012

DÍAZ FERNÁNDEZ, S. M. El plan de igualdad en el contexto educativo: un estudio de caso.Etic@net, Granada, v. 16, n. 1, p. 192-223, ene./jun. 2016. Disponível em: https://dialnet.unirioja.es/servlet/articulo?codigo=5909280. Acesso em: 11 set. 2017. 
DÍEZ PRIETO, A. Plan oficial para la mejora de la convivencia escolar. Educar(nos), Salamanca, n. 33, p. 6-9, 2006. Disponível em: https://dialnet. unirioja.es/servlet/articulo?codigo=2217253. Acesso em: 21 nov. 2017.

DUTERCQ, Y. Les régulations des politiques d'éducation. Rennes: Presseus Universitaires de Rennes, 2005.

ESPAÑA. Constitución Española [de 1978]. Boletín Oficial del Estado, Madrid, 29 dic. 1978.

ESPAÑA. Ley Orgánica nº 1, de 3 de octubre de 1990, de Ordenación General del Sistema Educativo [Logse]. Boletín Oficial del Estado, Madrid, 4 oct. 1990.

ESPAÑA. Ley Orgánica n ${ }^{\circ}$ 2, de 3 de mayo de 2006, de Educación [LOE]. Boletín Oficial del Estado, Madrid, 04 mayo 2006.

ESPAÑA. Ley Orgánica no 8, de 3 de julio de 1985, Reguladora del Derecho a la Educación [Lode]. Boletín Oficial del Estado, Madrid, 4 jul. 1985.

ESPAÑA. Ley Orgánica no ${ }^{8}$, de 9 de diciembre, de 2013, para la mejora de la calidad educativa [Lomce]. Boletín Oficial del Estado, Madrid, 10 dic. 2013.

ESPAÑA. Ministerio de Educación Cultura y Deporte. Plan de fomento de la lectura 2017-2020: Leer te da vidas extra. Madrid: MECD, 2017.

ESPAÑA. Ministerio de Educación y Ciencia. Ministerio da Cultura. Plan para la igualdad de oportunidades de las mujeres 1988-1990. Madrid: MEC; MC, 1987.

ESPAÑA. Ministerio de Educación y Ciencia. Plan Proa: Plan de Refuerzo, Orientación y Apoyo en Centros de Educación Primaria y Educación Secundaria. Madrid: MEC, 2007.

FUENTES PÉREZ, P. Hacia un concepto de planificación de la educación. Anales de Pedagogía, Murcia, n. 4, p. 89-102, 1986a. Disponível em: https://revistas.um.es/analespedagogia/article/view/288241/209421. Acesso em: 15 out. 2017.

FUENTES PÉREZ, P. Planificación de la educación: situación de la EGB en la Comunidad Autónoma de Murcia: estudio prospectivo. 1986b. Tese (Doctorado en Ciencias de la Educación) - Universidad de Murcia, Facultad de Filosofía y Ciencias de la Educación, Myrcuam 1986. 
GARCIA ALEGRE, E.; CASALS, M. C. ¿La corresponsabilidad es una estrategia de éxito? Revista de Educación, Madrid, n. extraordinario, p. 220-248, 2012. https://doi.org/10.4438/1988-592X-RE-2012-EXT-213

GONZALEZ FONTAO, M. P. El tratamiento de la diversidad en la Planificación educativa. Innovación Educativa, Santiago de Compostela, v. 8, p. 167-173, 1998. Disponível em: https://minerva.usc.es/xmlui/bitstream/ handle/10347/5224/pg_169-176_inneduc8.pdf?sequence=1\&isAllowed=y. Acesso em: 12 set. 2017.

GRAO RODRÍGUEZ, J. Planificación de la educación: ¿hasta dónde queremos ir?.In: GRAO RODRÍGUEZ, J. (coord.). Planificación de la educación y mercado de trabajo. Madrid: Narcea; Euskadi: Secretaría de la Presidencia del Gobierno Vasco, 1988. p. 35-43.

HERNÁNDEZ CASTILLA, R. Munticulturalidad y planificación educativa. In: MARTÍN BRIS, M. (ed.). Planificación educativa: intercambio de experiencias y perspectivas. Alcalá de Henares: Universidad de Alcalá, 2003. p. 47-60.

JABONERO BLANCO, M. El Plan de Educación Permanente de Adultas (PEPA): un ejemplo de la necesidad de decisiones políticas en materia de formación. Herramientas. Revista de Formación y Empleo, Barcelona, v. 3, n. 39, p. 28-29, 1995.

KAZAMIAS, A. M. Paideia e politeia: educação e Estado/Estado e sua cultura política na educação comparada. In: COWEN, R.; KAZAMIAS, A. M. (orgs.). Educação comparada: panorama internacional e perspectivas. Brasília, DF: UNESCO, CAPES, 2010. v. 1, p. 197-205.

LAVILLE, C.; DIONNE, J. A construção do saber: manual de metodologia da pesquisa em ciências humanas. Porto Alegre: Artmed; Belo Horizonte: Ed. UFMG, 1999.

LIMA, L. C. A escola como organização e a participação na organização escolar. Braga: Instituto de Educação e Psicologia, Centro de Estudos em Educação e Psicologia, Universidade do Minho, 1992.

LIMA, L. C. Modelos organizacionais de escola: perspectivas analíticas, teorias administrativas e o estudo da ação. In: MACHADO, L. M.; FERREIRA, N. S. C. (orgs.). Politicas e gestão da educação: dois olhares. Rio de Janeiro, DP\&A, 2002. p. 33-53. 
MAÑ̀̀ TERRÉ, T. El plan de fomento de la lectura del Ministerio de Cultura. In: MANITO, F. (coord.). Planificación estratégica de la cultura en España. Madrid: Ediciones y Publicaciones Autor S.R.L., 2008. p. 765-782.

MANZANARES MOYA, M. A. Evaluación del Plan Proa. Cuadernos de Pedagogía, Barcelona, n. 369, p. 77-80, jun. 2007.

MANZANARES MOYA, M. A.; ULLA DÍEZ, S. La evaluación estatal del Plan de Refuerzo, Orientación y Apoyo (Proa): análisis tras seis años de evaluación continuada. Revista de Educación, Madrid, n. extraordinario, p. 89-116, dec. 2012.

MAROY, C. Versunerégulation post-bureaucratique des systems d'enseignementen Europe? Les Cahiers de Recherche en Éducation et Formation, Louvain, n. 49, p. 3-26, déc. 2005.

MARTÍNEZ LOBERA, L.; BERNABÉ PÉREZ, C.; BLANCH HUGUET, R. El Plan Educativo de Entorno de Barberà del Vallès. Aula de Innovación Educativa, Barcelona, v. 15, n. 149, p. 75-80, 2006.

MARTÍNEZ SALAZAR, J. J. Bases para la formulación de un modelo de planificación de recursos educativos. In: GRAO RODRÍGUEZ, J. (coord.). Planificación de la educación y mercado de trabajo. Madrid: Narcea; Euskadi: Secretaria de la Presidencia del Gobierno Vasco, 1988. p. 97-112.

MARTINS, P. S. Planejamento e plano nacional de educação. Cadernos Aslegis, Brasília, n. 39, p. 91-118, jan./abr. 2012.

MASON, M. Comparação entre culturas. In: BRAY, M.; ADAMSON, B.; MASON, M. (Orgs.). Pesquisa em educação comparada: abordagens e métodos. Brasília, DF: Liber Livro, 2015, p. 255-292.

MIGUEL DÍAZ, M. et al. Evaluación de la inserción laboral de los participantes en la Formación Profesional para el empleo en Asturias. Revista de Educación, Madrid, n. 358, p. 599-616, mayo/ago. 2012.

MONARCA, H. et al. Política y cambio en educación: el caso de las competencias básicas en España. Ensaio: Avaliação e Políticas Públicas em Educação, Rio de Janeiro, v. 24, p. 968-989, out./dez. 2016. https://doi.org/10.1590/S0104-40362016000400009

MONLEVADE, J. A. C. Plano municipal da educação: fazer para acontecer. Brasília, DF: Idéa, 2002. 
MONTERO ESPINOZA, V. Aspectos de la planificación en la administración educativa. Educar, Barcelona, n. 6, p. 35-57, 1984.

OLAYA VILLAR, M. D. Los documentos del Plan Experimental de Educación Infantil. Revista Interuniversitaria de Formación del Profesorado, Zaragoza, n. 25, p. 167-174, 1996. Disponível em: https://dialnet.unirioja.es/ servlet/articulo?codigo=117901. Acesso em: 12 set. 2017.

QUINTANA CABANAS, J. M. Planificación educacional y empleo. Aula Abierta, Oviedo, n. 40, p. 43-69, 1984. Disponível em: https://dialnet.unirioja. es/servlet/articulo?codigo=2365169. Acesso em: 12 set. 2017.

RAMOS ALÍA, J. F. La respuesta educativa al alumnado con altas capacidades desde el enfoque curricular: del plan de atención a la diversidad a las adaptaciones curriculares individuales. FAISCA. Revista de Altas Capacidades, Madrid, v. 13, n. 15, p. 40-49, 2008. Disponível em: https:// dialnet.unirioja.es/servlet/articulo?codigo=3539199. Acesso em: 26 jan. 2018.

REBOLLO CATALÁN, M. A.; VEGA CARO, L.; GARCÍA PÉREZ, R. El profesorado en la aplicación de planes de igualdad: conflictos y discursos en el cambio educativo. Revista de Investigación Educativa, Barcelona, v. 29, n. 2, p. 311-324, 2011. Disponível em: https://core.ac.uk/download/pdf/41554666. pdf. Acesso em: 29 set. 2017.

RINCÓN VERDERA, J. C.; VALLESPIR SOLER, J. El tratamiento de la interculturalidad en los centros de primaria de las Islas Baleares, según las programaciones generales anuales: el Plan de Acogida Lingüística y Cultural. Revista de Educación, Madrid, n. 353, p. 415-441, set./dic. 2010. Disponível em: https://dialnet.unirioja.es/servlet/articulo?codigo=3288027. Acesso em: 1 nov. 2017.

ROBERTSON, S.; DALE, R. Além dos "ismos" metodológicos na educação comparada em uma era de globalização. In: COWEN, R.; KAZAMIAS, A. M. (orgs.). Educação comparada: panorama internacional e perspectivas. Brasília: UNESCO, CAPES, 2010. v. 2 , p. $555-572$.

ROCHA, D. C. C.; MONLEVADE, J. A. C.; AGUIAR, R. R. Financiamento e gestão orçamentária da educação. In: BRASIL. Ministério da Educação. Secretaria de Educação Básica. Pradime: Programa de Apoio aos Dirigentes Municipais de Educa. Brasília, DF: MEC. SEB, 2006. p. 73-118. 
RODRÍGUEZ GONZÁLEZ, A. M. Modelos de atención a la diversidad en educación secundaria obligatoria: análisis comparativo de los planes de atención a la diversidad de las comunidades autónomas de Andalucía y de la Región de Murcia. Revista de Educación Inclusiva, Almeria, v. 6, n. 3, p. 41-64, 2013. http://riberdis.cedd.net/handle/11181/4235. Acesso em: 27 jan. 2018.

SANZ ORO, R. Planificación de la educación en la provincia de Santa Cruz de Tenerife en los niveles de Educación Preescolar y General Basica. València, 1980. Tese (Doutorado em Ciências da Educação) - Universitat de València, Facultat de Filosofia i Ciencies de l'Educació, València.

SEBASTIAN HEREDERO, E. La planificación de la atención a la diversidad. In: MARTÍN BRIS, M. (ed.). Planificación educativa: intercambio de experiencias y perspectivas. Alcalá de Henares: Universidad de Alcalá, 2003. p. 29-46.

SOUZA, D. B. Relatório técnico-científico. Estágio Sênior no ExteriorPolíticas públicas de planejamento da educação no Brasil e na Espanha: estudo comparado sobre os planos nacionais de educação no contexto da descentralização político-administrativa entre os poderes centrais, regionais e locais. Granada, Espanha: UGR (digitalizado), 12 fev. 2018.

SOUZA, D. B.; BATISTA, N. C. Educação comparada Brasil-Espanha: estado da arte 1990-2014. Ensaio: Avaliação e Políticas Públicas em Educação, Rio de Janeiro, v. 26, n. 100, p. 723-758, jul./set. 2018. https://doi.org/10.1590/s0104-40362018002601046.

SOUZA, D. B.; BATISTA, N. C. Perspectiva comparada em políticas públicas de educação: Estudos Brasil-Espanha. Education Policy Analysis Archives, Arizona, v. 25, n. 19, p. 19-43, mar. 2017. https://doi.org/10.14507/epaa.25.2548

STEINER-KHAMSI, G. Reterritorializing educational import. In: NÓVOA, A.; LAWN, M. (eds.). Fabricating Europe: the formation of an education space. Dordrech: Kluver Academic Publisher, 2002. p. 69-86.

TEM RICART, A. Planificación de la educación preescolar y E.G.B. en la provincia de Castellon: modelo Asat-88. València, 1988. Tese (Doctorado en Ciencias de la Educación) - Universitat de València, Facultat de Filosofia i Ciencies de l'Educació, Departament de Teoria de l'Educació, València. 
TORREGO SEIJO, J. C. Convivencia y aprendizaje en elmarco de un modelo integrado. In: TORREGO SEIJO, J. C. (coord.). Plan de convivencia: fundamentos y recursos para su elaboración y desarrollo. Madrid: Alianza Editorial, 2008. p. 19-43.

VIEIRA, S. L. Planos e políticas educacionais: das concepções às práticas no Brasil. In: SOUZA, D. B.; MARTINS, A. M. (orgs.). Planos de educação no Brasil: planejamentos, políticas, práticas. São Paulo: Loyola, 2014. p. 55-71.

\section{Informações sobre o autor}

Donaldo Bello de Souza: Professor Titular no Departamento de Políticas Públicas, Avaliação e Gestão da Educação, da Faculdade de Educação da Universidade do Estado do Rio de Janeiro. Doutorado em Educação pela Universidade Federal do Rio de Janeiro. Pós-Doutorado em Políticas Educacionais Comparadas pela Facultad de Ciencias de la Educación da Universidad de Granada e em Política e Administração Educacional pela Faculdade de Psicologia e de Ciências da Educação da Universidade de Lisboa. Contato: donaldobello@gmail.com

iD https://orcid.org/0000-0002-9146-5254 